\title{
Pengaruh Modal Intelektual Dan Kepemimpinan Kewirausahaan Sebagai Pemoderasi Pada Kinerja Dengan Keunggulan Kompetitif Sebagai Pemediasi Di Perguruan Tinggi Swasta
}

\author{
Eni Cahyani ${ }^{1}$, Asri Laksmi Riani ${ }^{2}$ \\ Politeknik Anika ${ }^{1}$, Universitas Sebelas Maret ${ }^{2}$ \\ eniegan@gmail.com
}

\section{Article History}

received $1 / 9 / 2021$

revised $1 / 10 / 2021$

accepted 1/11/2021

\begin{abstract}
This study aims to develop science, especially intellectual models (model of human, structural, relational, and technology), entrepreneurial leadership as a moderator variable based on the competitive advantage of private colleges. The study used a qualitative approach to causal relationships between variables. The questionnaire is designed to evaluate the research model with a sample of the leaders of private colleges in LLDIKTI region II. To assess the reliability and validity of all construct sizes, an analysis of conformity factors is carried out using AMOS 21 application. The results of this study is described about the proposed model fit, intellectual capital and entrepreneurial leadership with positively correlated with competitive advantage and performance. The strongest of influence of the 4 (four) elements discussed, as follows: structure, technology, relational, and human. Intellectual capital is moderated by entrepreneurial leadership variables on competitive advantage and then the private colleges performance has a positive influence. Intellectual capital mediated by competitive advantages on performance indirectly has the same result. Meanwhile, entrepreneurship leadership that moderates the relationship between intellectual capital and competitive advantage is not significant. The model's recommendations, designed to help the leaders of private colleges make decisions, remind your changing environment and then will affect organizational performance. The limitation of this study is the questionnaire of the number and uneven spread of samples. In the future, it is expected that other researchers can add spiritual capital, which is very fundamental in shaping human behavior.
\end{abstract}

Keywords: intellectual model, leadership, entrepreneurship, superiority, competitive, and performance

\begin{abstract}
Abstrak
Penelitian ini bertujuan untuk mengembangkan ilmu pengetahuan khususnya modal intelektual (modal manusia, struktural, relasional dan teknologi), kepemimpinan kewirausahaan sebagai variabel moderator yang dimediasi oleh keunggulan kompetitif pada kinerja Perguruan Tinggi Swasta (PTS). Penelitian ini menggunakan pendekatan kuantitatif dengan hubungan kausal antar variabel. Kuesioner dirancang untuk mengevaluasi model penelitian dengan sampel pimpinan PTS di LLDIKTI Wilayah II. Untuk menilai reliabilitas dan validitas pada semua ukuran konstruk, dilakukan analisis faktor kesesuaian (CFA) dengan menggunakan AMOS 21. Hasil penelitian menunjukkan bahwa model yang diusulkan fit, modal intelektual dan kepemimpinan kewirausahaan berkorelasi positif dengan keunggulan kompetitif dan kinerja. Pengaruh terkuat dari 4 (empat) elemen yang dibahas yaitu struktur, teknologi, relasional dan manusia. Modal intektual dimoderasi variabel kepemimpinan kewirausahaan pada keunggulan kompetitif dan kinerja PTS memiliki pengaruh positif. Modal intelektual dimediasi oleh keunggulan kompetitif pada kinerja secara tidak langsung memiliki hasil yang sama. Sedangkan, kepemimpinan kewirausahaan yang memoderasi hubungan antara modal intelektual dengan keunggulan kompetitif tidak signifikan. Rekomendasi model ini, dirancang untuk membantu pimpinan PTS dalam pengambilan keputusan, mengingat lingkungan terus mengalami perubahan dan akan mempengaruhi kinerja organisasi. Keterbatasan penelitian adalah kuesioner jumlah dan penyebaran sampel yang belum merata. Ke depan, diharapkan peneliti lain dapat menambahkan modal spiritual, yang sangat fundamental dalam membentuk perilaku manusia.

Kata kunci: Modal Intelektual, Kepemimpinan Kewirausahaan, Keunggulan Kompetitif dan Kinerja
\end{abstract}

Social, Humanities, and Education Studies (SHEs): Conference Series

p-ISSN 2620-9284

https://jurnal.uns.ac.id/shes

e-ISSN 2620-9292

This work is licensed under a Creative Commons Attribution-ShareAlike 4.0

International License. 


\section{PENDAHULUAN}

Sejak tahun 2015 sampai 2019 Kemenristekdikti telah menutup 130 Perguruan Tinggi Swasta (PTS), Nasir menyebutkan 3 (tiga) alasan menutup PTS yaitu tidak ada proses pembelajaran, jumlah mahasiswa dan penyalahgunaan wewenang (https://www.cnnindonesia.com/). Selain itu, alasan lainnya seperti Permenristekdikti Nomor 3 Tahun 2018 tentang penggabungan dan penyatuan PTS, kebijakan-kebijakan yang semakin mewajibkan peningkatan kualitas serta ketidakmampuan bersaing.

Di sisi lain, dikatakan otonomi dan tata kelola PT merupakan perjuangan bagaimana menyiasati beragam kepentingan yang melingkupinya. Hal ini mempengaruhi berbagai kepentingan tata kelola seperti kekuatan pasar, peran pemerintah, dan kehidupan akademik yang termasuk upaya mencapai keunggulan dan kebebasan akademik (Soetjipto, dkk. 2014). Wujud otonomi itu diantaranya penerimaan mahasiswa baru. Hal ini memperlihatkan kesenjangan jumlah penerimaan mahasiswa baru PTN dan PTS jika dibandingkan dengan Jumlah PTS sebanyak 4.183 PT sedangkan 400 PTN (https://pddikti.kemdikbud.go.id). PTS sebagai bagian dari entitas bisnis, akan menghadapi tantangan globalisasi baik organisasi yang berorientasi nonprofit, Rohim dan Budhiasa, (2019), adanya perubahan lingkungan dari kompetitif menjadi dinamis dan perubahan tersebut bersifat mutlak dan tidak dapat dihindarkan. Wen-Min Lu, (2012) akibatnya manajer Universitas dalam hal ini pimpinan perlu alokasi sumber daya dan keunggulan kompetitif, pengambilan keputusan strategis perlu dilakukan, terutama mengenai gaya operasional dalam kondisi persaingan yang ketat ini.

Pada dasarnya setiap organisasi memiliki keinginan untuk lebih unggul dari pesaingnya. Lebih lanjut dijelaskan bahwa keunggulan bersaing (competitive advantage) memiliki 2 (dua) hal berbeda namun saling berkaitan. Pertama menekankan pada keunggulan dalam hal sumber daya dan keahlian yang dimiliki organisasi. Smriti dan Das (2018) pandangan berbasis sumber daya menekankan pada strategi kompetitif dengan memanfaatkan sumber daya yang ada dalam suatu organisasi. Warnelfelt (1984) menyebutkan bahwa sumber daya meliputi sumber daya yang tangible dan intangible aset yang terikat pada organisasi. Dollinger (1999), mengelompokkan pengukuran sumber daya menjadi 6 indikator yang mampu menciptakan keunggulan bersaing yang berkelanjutan diantaranya intelektual/manusia.

Penekanan keunggulan kompetitif yang kedua pada keunggulan dalam pencapaian kinerja. Preffer (1977) beberapa peneliti berasumsi bahwa kepemimpinan berkaitan dengan kinerja organisasi. Yukl (2015) juga menjelaskan eksekutif puncak memiliki pengaruh besar pada kinerja organisasi. Ruky, (2001) kepemimpinan merupakan salah satu faktor yang dapat mempengaruhi kinerja organisasi, Keskes et. al. (2018) sebagai upaya untuk mengendalikan anggota organisasi agar bekerja sesuai dengan standar dan tujuan organisasi. Hal ini diperjelas Hadijah et al. (2015) menyatakan bahwa pemimpin secara umum dapat menggunakan perubahan budaya yang dibutuhkan dalam memfasilitasi penyelarasan nilai dalam organisasi, penting bahwa para pemimpin menyediakan umpan balik tentang aspek kinerja yang beragam dari para pengikut, terutama yang dapat mempengaruhi keefektifan diri mereka, meningkatkan kepuasan kerja, dan mengenali bidang perbaikan. Smart \& Conant (1994) mengungkapkan bahwa organisasi dengan orientasi kewirausahaan yang tinggi memiliki hasil kinerja yang lebih baik dibanding dengan organisasi lain. Ireland, et. al, (2003) ada banyak kepemimpinan diantaranya kepemimpinan kewirausahaan, didefinisikan sebagai kemampuan untuk mengelola sumber daya yang tersedia untuk mencari peluang dan keuntungan dengan cara yang strategis. Renko et al.,(2013), gaya kepemimpinan khas yang dapat hadir dalam organisasi dari berbagai ukuran, jenis, atau usia.

PTS melakukan upaya untuk mewujudkan keunggulan kompetitif dan kinerja agar memuaskan semua stakeholder baik internal dan eksternal. Selain itu, sosok pemimpin akan berperan penting untuk menciptakan kinerja maksimal, guna mencapai tujuan organisasi yang telah ditetapkan. Peneliti mengamati kinerja PTS di Lembaga Layanan Pendidikan Tinggi (LLDIKTI) wilayah II meliputi 4 (empat) provinsi yaitu: Sumatera Selatan, 
SHEs: Conference Series 5 (1) (2022) 104- 113

Lampung, Bengkulu dan Kepulauan Bangka Belitung. PTS yang ada di lingkungan LLDIKTI Wilayah II berjumlah 205 PTS dengan 847 program studi yang aktif pada pangkalan data perguruan tinggi. Peneliti telah mendata kinerja PTS melalui tabel di bawah ini.

Tabel 1. Kinerja PTS

\begin{tabular}{|c|c|c|c|c|}
\hline \multicolumn{5}{|l|}{ Keterangan } \\
\hline Klaster & 3 & 4 & 5 & $\begin{array}{ll}\text { Tidak } & \text { memiliki } \\
\text { klaster } & \end{array}$ \\
\hline Akreditasi & $\begin{array}{l}1,46 \% \\
A \\
2,33\end{array}$ & $\begin{array}{l}8,29 \% \\
B \\
52,44\end{array}$ & $\begin{array}{l}53,17 \% \\
C \\
45,23\end{array}$ & $\begin{array}{l}37,07 \% \\
\text { Belum Terakreditasi } \\
0\end{array}$ \\
\hline $\begin{array}{l}\text { Jabatan } \\
\text { akademik }\end{array}$ & $\mathrm{AA}$ & Lektor & $\begin{array}{l}\text { Lektor } \\
\text { Kepala }\end{array}$ & Profesor \\
\hline Pendidikan & $\begin{array}{l}29 \% \\
\mathrm{~S} 1 \\
0\end{array}$ & $\begin{array}{l}17,46 \% \\
\text { S2 } \\
92,21 \%\end{array}$ & $\begin{array}{l}3,86 \% \\
\text { S3 } \\
7,79 \%\end{array}$ & $0,30 \%$ \\
\hline
\end{tabular}

Sumber: kepala LLDIKTI Wilayah II, September 2020

Tabel di atas menunjukkan kinerja PTS masih perlu ditingkatkan, terlihat bahwa $37,07 \%$ PTS belum memiliki klaster dan $53,17 \%$ klister 5 . Akreditasi A hanya $2,33 \%$ dari 857 Program Studi yang berasal dari 205 PTS. Kemudian Jabatan akademik (JJA) khususnya professor $0,30 \%$ dan jenjang Pendidikan dosen S2 mendominasi sebesar $92,21 \%$, sedangkan S3 hanya drbesar 7,79\%. Selanjutnya kinerja penelitian dan pengabdian kepada masyarakat ditunjukkan pada tabel 2.

Tabel 2. Jumlah Dana Penelitian PTS LLDIKTI Wilayah II

\begin{tabular}{lllllll}
\hline No & Tahun & PTS & \multicolumn{4}{c}{ Dana } \\
\cline { 4 - 7 } & & & Penelitian & Pengabdian & PKM & Total \\
1 & 2017 & 59 & 16.005 .817 .000 & 2.154 .480 .000 & 188.250 .000 & 18.348 .547 .000 \\
2 & 2018 & 73 & 19.574 .303 .000 & 2.227 .000 .000 & 171.000 .000 & 21.972 .303 .000 \\
3 & 2019 & 68 & 16.471 .658 .950 & 2.876 .700 .000 & 202.700 .000 & 19.551 .058 .950 \\
\hline
\end{tabular}

Sumber: LLDIKTI Wilayah 2, Mei 2019

Tabel di atas menunjukkan kinerja PTS belum baik jika dibandingkan dengan LLDIKTI wilayah lainnya, hal tersebut disampaikan oleh Kepala LLDIKTI Wilayah II pada saat penandatangan kontrak penelitian dan pengabdian tahun 2019, perlu kerja keras bersama untuk mencapai kata unggul dalam bidang ini.

Peneliti mengamati bahwa pengaruh modal intelektual terhadap kinerja masih ada fenomena gap peluang untuk dilakukan penelitian lanjut guna mengisi celah tersebut. Maka peneliti mengajuhkan variabel kepemimpinan kewirausahaan. Sandybayev, et al (2019) di mana temuan utamanya mengungkapkan bahwa kepemimpinan berpola pikir kewirausahaan mendapat manfaat lebih dari kepemimpinannya untuk meningkatkan kinerja organisasi. Ibarra et. al (2019) bahwa "modal intelektual menyediakan sumber daya dan kemampuan untuk menciptakan keunggulan kompetitif yang berkelanjutan di organisasi". Selain itu, kepemimpinan kewirausahaan sebagai variabel mediator berperan di dalam memposisikan organisasi untuk menangkap peluang dan meningkatkan kemampuan organisasi untuk menciptakan variasi yang diperlukan untuk bersaing dengan lingkungan yang sangat tidak dapat diprediksi (Renko et al., 2014). 
METODE

Tipe penelitian ini adalah fundamental yang bertujuan berpartisipasi dalam pengembangan ilmu pengetahuan (Sekaran dan Bougie, 2016). Unit analisinya organisasi, jenis data yang digunakan data primer dan sekunder. Pengumpulan data selama 1 (satu) bulan, instrumen kuesioner yang didistribusikan melalui Whatsapp menggunakan aplikasi google form karena masa Pandemic Covid-19. Populasi penelitian ini adalah PTS, di bawah LLDIKTI wilayah II (Sumatera Selatan, Lampung, Bangka Belitung dan Bengkulu) berjumlah 205, informannya pimpinan. Sampel jenuh dipilih sebagai tekniknya dengan mempertimbangkan bahwa semua PTS dipengaruhi oleh internal (sumber daya) dan eksternal (kebijakan). Data terkumpul sebanyak 59 kuesioner atau 28,78\%. Pengukuran variabel menggunakan instrument kuesioner baku yang diambil dari penelitian terdahulu. Skala yang digunakan adalah skala likert dengan rentang nilai 1 (sangat tidak setuju) sampai 5 (sangat setuju). Setiap variabel akan diwakilkan dengan pertanyaan-pertanyaan baku yang peneliti modifikasi sesuai dengan kebutuhan penelitian ini. Variabel modal intelektual, yang direpresentasikan oleh 4 dimensi. variabel modal manusia diadaptasi dari Bontis, 1998; Abualoush et al., (2018), modal struktural dan modal relasional diadaptasi dari Hussinki et al. (2017) dan Kamukama dan Sulait (2017). Modal teknologi diadaptasi dari Khalique, et al, (2019). Variabel Kepemimpinan kewirausahaan di adaptasi dari Gupta, MacMillan \& Surie, (2004).

Variabel keunggulan kompetitif mengadaptasi dari Li et al., (2006). Variabel kinerja sangat kompleks mencakup banyak elemen dan dapat menggunakan pendekatan multidimensi, (Thapa, 2015). Pengukuran variabel ini menggunakan pendekatan subjektif berdasarkan persepsi manajemen organisasi (Beltramino, et al, 2020). Pengukuran kinerja PTS mengacu pada indikator Kinerja Utama (IKU) Keputusan Menteri Pendidikan dan Kebudayaan Nomor: 754/P/2020. Indikator pertanyaan IKU berasal matriks penilaian laporan evaluasi diri dan laporan kinerja PT. Tahapan analisis digambarkan dengan path diagram untuk menganalisis logika keterkaitan dan urutan kejadian diantara variabel. Untuk menilai reliabilitas dan validitas semua ukuran konstruk, analisis faktor kesesuaian (CFA) dilakukan dengan menggunakan perangkat lunak AMOS 21. Pengujian konsistensi dan akurasi jawaban terhadap kuesioner juga dilakukan dengan normalitas dan outlier agar diperoleh generalisasi yang cukup baik. Penyimpangan terhadap criteria multivariate normality dapat dilihat dari hasil estimasi parameter bootstrspping data penelitian.

Pengujian Hipotesis nol (Ho) dilakukan jika Critical Ratio $(\mathrm{CR})>5 \%$, Sedangkan penolakan hipotesis jika nilai $\mathrm{CR}<5 \%$. Selanjutnya tidak bisa menolak Ho jika nilai $\mathrm{CR}$ parameter $\beta$ lebih kecil dari nilai 1,96 atau menolak hipotesis $\beta=0$ jika CR parameter $\beta$ lebih kecil dari 1,96 atau menolak hipotesis $\beta=0$. Faktor loading untuk setiap item konstruksi melebihi nilai ambang 0,50 dan koefisien alpha Cronbach dari semua konstruksi lebih besar dari 0,75. Pengujian variabel moderating dilakukan dengan Uji Interaksi (Moderated Regression Analysis). Uji Selisih Mutlak, untuk menguji moderasi dengan model selisih dari variabel independent. Kemudian, pengujian moderating menggunakan residual untuk menguji deviasi dari model pada lack of fit (ketidakcocokan) yang dihasilkan dari deviasi hubungan linear antar variabel independent.

\section{HASIL DAN PEMBAHASAN}

Analisis hasil pengolahan data pada tahap full model SEM dilakukan dengan melakukan uji kesesuaian dan uji statistik ditampilkan pada Gambar 2. 


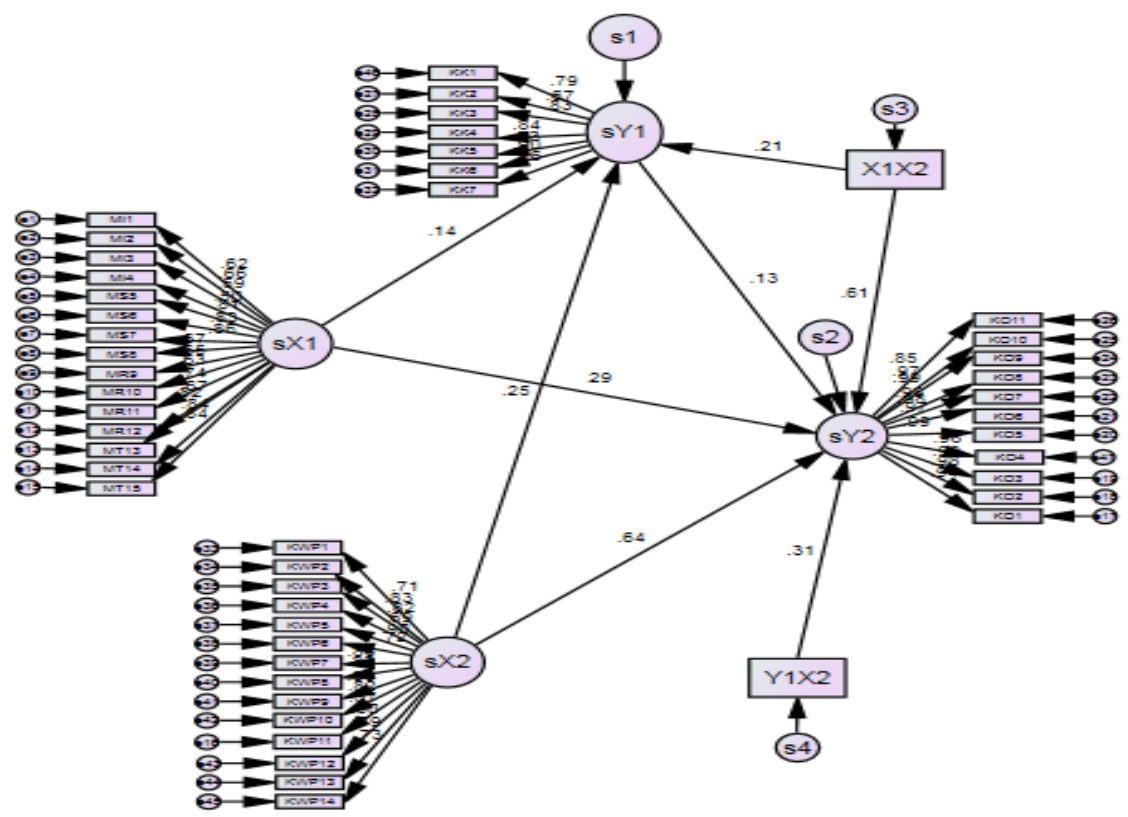

Gambar 2. Hasil Pengujian Structural Equation Model

Uji terhadap kelayakan full model SEM ini diringkas sebagaimana dalam tabel berikut:

Tabel 3. Hasil Pengujian Kelayakan Model Structural Equation Model

\begin{tabular}{|c|c|c|c|}
\hline $\begin{array}{l}\text { Goodness of fit } \\
\text { Indeks }\end{array}$ & Cut of value & Hasil & Evaluasi Model \\
\hline Chi - Square & 566,8 & 2750.991 & - \\
\hline Probabilitas & $>0,005$ & 0.00 & - \\
\hline CMIN/DF & $<2.00$ & 1.0268 & Memenuhi \\
\hline RMSEA & $<0.08$ & .158 & Tidak memenuhi \\
\hline GFI & $>0.90$ & .983 & Memenuhi \\
\hline TLI & $>0.90$ & .996 & Memenuhi \\
\hline
\end{tabular}

Sumber: Data primer yang diolah, 2021

Hasil tersebut menunjukkan bahwa model yang digunakan dapat diterima, dimana Indeks pengukuran TLI, CMIN/DF, berada dalam rentang nilai yang diharapkan. Nilai GFI dan AGFI juga memenuhi. Dengan demikian uji kelayakan model SEM sudah memenuhi syarat penerimaan. Maka pengujian parameter sebagaimana yang dihipotesiskan dapat diinterpretasikan. Hasil pengujian parameter diperoleh sebagai berikut:

Tabel 4. Regression dan Standardized Regression Weights

\begin{tabular}{lllllll}
\hline & & & Estimate & S.E. & C.R & P \\
\hline sY1 & $<---$ & sX1 & .144 & .106 & 2.302 & .028 \\
sY2 & $<---$ & sX1 & .248 & .172 & 5.034 & $* * *$ \\
sY1 & $<---$ & sX2 & .213 & .118 & 2.898 & .048 \\
sY1 & $<---$ & X1X2 & .134 & .000 & 1.647 & .100 \\
sY2 & $<---$ & sY1 & .290 & .050 & 4.691 & $* * *$ \\
sY2 & $<---$ & X1X2 & .640 & .000 & 11.255 & $* * *$ \\
sY2 & $<---$ & Y1X1 & .610 & .242 & 6.421 & $* * *$ \\
sY2 & $<---$ & Y1X2 & .313 & .000 & 9.618 & $* * *$ \\
\hline
\end{tabular}


Untuk uji validitas (CFA) ditunjukkan di gambar 2 bahwa nilai indikator variabel di atas memenuhi $>0,05$. Berdasarkan hasil diperoleh bahwa semua koefisien jalur memiliki arah koefisien positif. Pengujian Hiipotesis $\mathrm{H} 1$, parameter estimasi hubungan modal intelektual (X1) terhadap keunggulan kompetitif $(Y 1)$ menunjukkan nilai pengujian $C . R=2.302$ dengan probabilitas $=0,028<0,05$. Nilai signifikansi yang lebih kecil dari 0,05 menunjukkan bahwa modal intelektual memiliki pengaruh yang signifikan terhadap Keunggulan kompetitif.

Selanjutnya $\mathrm{H} 2$, parameter estimasi hubungan modal intelektual (X1) terhadap kinerja (Y2) menunjukkan Nilai pengujian C.R $=5.034$ dengan probabilitas $=0,00<0,05$. Nilai menunjukkan ada pengaruh yang signifikan. Berdasarkan standardized regression weights untuk setiap dimensi modal intelektual yang memiliki peran terkuat adalah modal struktur memiliki koefisien/nilai estimate (.859), teknologi (.842), relasional (.735), dan manusia (.664). H3, parameter estimasi hubungan kepemimpinan kewirausahaan (X2) terhadap Keunggulan kompetitif $(\mathrm{Y} 1)$ menunjukkan Nilai pengujian $\mathrm{C} . \mathrm{R}=2.898$ dengan probabilitas $=$ $0,048<0,05$. Nilai menunjukkan bahwa Kepemimpinan kompetitif memiliki pengaruh yang signifikan terhadap keunggulan Kompetitif.

$\mathrm{H} 4$, parameter estimasi hubungan kepemimpinan kewirausahaan (X2) memoderasi modal intelektual (X1) terhadap Keunggulan kompetitif (Y1) menunjukkan Nilai pengujian C. $R=1.647$ dengan probabilitas $=0,100<0,05$, bahwa Kepemimpinan kewirausahaan memoderasi tidak memiliki pengaruh yang signifikan terhadap keunggulan Kompetitif. Kemudian H5, parameter estimasi hubungan Keunggulan kompetitif (Y1) terhadap Kinerja (Y2) menunjukkan nilai pengujian C.R $=4.691$ dengan probabilitas $=0,00<0,05$. Nilai menunjukkan bahwa keunggulan kompetitif berpengaruh yang signifikan terhadap kinerja.

Kemudian kepemimpinan kewirausahaan (X2) terhadap kinerja (Y2) menunjukkan nilai pengujian $C . R=6.421$ dengan probabilitas $=0,00<0,05$. Nilai menunjukkan ada pengaruh yang signifikan. Selanjutnya H6, kepemimpinan kewirausahaaan (X2) memoderasi modal intelektual (X1) dengan kinerja (Y2) menunjukan nilai pengujian $\mathrm{CR}=$ 11.255 dengan probabilitas $0.00<0,05$ menunjukkan bahwa berpengaruh signifikan. $\mathrm{H} 7$, Modal intelektual (X1) dimediasi keunggulan kompetitif (Y1) terhadap kinerja (Y2) menunjukkan Nilai pengujian C.R $=6.421$ dengan probabilitas $=0,00<0,05$, artinya idukung. Pengujian terakhir pada $\mathrm{H} 8$, hubungan keunggulan kompetitif (Y1) memediasi dengan kinerja nilai $\mathrm{C} . \mathrm{R}=9.618$ dengan probabilitas $0.00<0.05$ menunjukkan ada pengaruh signifikan. Jadi dapat disimpulkan bahwa dari hipotesis yang diajuhkan $\mathrm{H} 1, \mathrm{H} 2$, $\mathrm{H} 3, \mathrm{H} 5, \mathrm{H} 6, \mathrm{H} 7, \mathrm{H} 8$ didukung sedangkan $\mathrm{H} 4$ ditolak.

Hasil pengujian $\mathrm{H} 1$ memberikan bukti empiris yang mendukung hasil penelitian Zhang et al., (2018), modal intelektual menghasilkan nilai yang mendukung keunggulan kompetitif di masa depan. H2 sejalan dengan hasil penelitian Ibarra et. al. (2019) yang menunjukkan bahwa modal intelektual berpengaruh positif dan signifikan terhadap kinerja. Namun ada yang cukup berbeda dengan hasil penelitian yang lain bahwa elemen yang terkuat dari modal intelektual pada objek penelitian ini adalah modal structural. Hasil ini sangat relevan, karena secara fundamental setiap PTS, pelaksanaan proses operasional dan pembelajaran mengacu kebijakan, proses, prosedur Sistem Penjaminan Mutu Internal. PTS memiliki pengetahuan yang berguna dalam dokumen dan database. Kedua modal teknologi pemanfaatan TIK yang efektif berdampak positif pada inovasi output (civitas akademik) dan proses (Mohsin et al., 2013). PTS harus berkoordinasi antar departemen sehingga sangat penting untuk inovasi teknologi. Ketiga modal relasional, PTS dan pemangku kepentingan eksternal sering bekerja sama untuk menyelesaikan masalah akan meningkatkan kinerjanya. Terakhir modal manusia bahwa kinerja PTS akan meningkat jika memiliki tenaga pendidikan dan pendidik kreatif dan cerdas. Hasil ini sedikit berbeda dengan penelitian sebelumnya dengan bentuk organisasi lainnya yang menyebutkan manusia dan relasional terkuat dan structural tidak berpengaruh terhadap kinerja (Bontis, et al 2018).

Hasil H5, bahwa kepemimpinan kewirausahaan memoderasi modal intelektual dengan kinerja. Peneliti berpendapat bahwa semakin organisasi memberikan dukungan terhadap peningkatan modal intelektual maka kinerja PTS akan semakin meningkat, dan sebaliknya. H3, Kepemimpinan kewirausahaan berpengaruh positif pada keunggulan kompetitif hasilnya didukung. Hal ini sejalan Chang et al., (2019) Kepemimpinan yang 


\section{SHEs: Conference Series 5 (1) (2022) 104- 113}

efektif dapat berperan sebagai instrumen penting dalam berbagi informasi dan pengetahuan dalam organisasi, sehingga keputusan yang tepat waktu dan realistis dapat diambil. Dalam penelitian ini kepemimpinan kewirausahaan di PTS, memiliki peran yang paling kuat yaitu menyerap ketidakpastian. Selanjutnya $\mathrm{H} 6$, hasilnya kepemimpinan kewirausahaan berpengaruh positif terhadap kinerja PTS, hal ini sejalan dengan penelitian Miao et al., (2018) dan Rahim et al, (2015) pemimpin berfokus pada inisiatif kewirausahaan untuk memastikan kinerja organisasi yang lebih baik.

$\mathrm{H} 7$ didukung, bahwa kemampuan pemimpin ini akan mengeksploitasi lingkungan untuk menciptakan peluang, memanfaatkan perubahan sehingga mengembangkan keunggulan kompetitif akhirnya berdampak pada kinerja PTS yang lebih baik dan tahan lama (Sarabi et al., 2020). Keunggulan kompetitif memediasi hubungan antara modal intelektual dan kinerja organisasi, berarti bahwa PTS perlu terus meningkatkan upaya untuk meningkatkan modal intelektual sehingga menghasilkan keunggulan kompetitif lebih kuat. Pada hipotesis terakhir hasilnya didukung penelitian Miao et al., (2018) dan Rahim et al, (2015) mengungkapkan untuk memastikan keunggulan kompetitif bergerak dinamis para pemimpin yang berfokus pada inisiatif kewirausahaan memastikan kinerja organisasi yang lebih baik. Sarabi et al., (2020) dengan mengeksploitasi lingkungan untuk menciptakan peluang, memanfaatkan perubahan dan mengembangkan keunggulan kompetitif untuk kinerja yang lebih baik dan tahan lama.

\section{SIMPULAN}

Dapat disimpulkan bahwa dari 8 hipotesis yang diajuhkan, ada 7 hipotesis yang didukung artinya kepemimpinan kewirausahaan dapat menjadi variabel independen maupun pemoderasi bagi variabel modal intelektual dan kinerja PTS tetapi tidak memoderasi modal intelektual dengan keunggulan kompetitif. Studi ini berkontribusi secara teoritis bagi literatur kepemimpinan kewirausahaan. Kemudian secara praktis membantu pimpinan PTS dalam pengambilan keputusan, mengingat lingkungan terus mengalami perubahan dan akan mempengaruhi kinerja organisasi. Keterbatasan dari penelitian ini adalah penyebaran kuesioner yang belum merata. Ke depan, diharapkan peneliti lain dapat menambahkan modal spiritual, yang sangat fundamental dalam membentuk perilaku manusia

\section{DAFTAR PUSTAKA}

Abualoush, S., Masa'deh, R., Bataineh, K. and Alrowwad, A. (2018), "The role of knowledge management process and intellectual capital as intermediary variables between knowledge management infrastructure and organization performance", Interdisciplinary Journal of Information, Knowledge, and Management, Vol. 13, pp 279-309.

Abubakar, L.S., Zainol, F.A. and Daud, W.N.B.W. 2018, "Entrepreneurial leadership and performance of small and medium sized enterprises: a structural equation modelling approach", Journal for International Business and Entrepreneurship Development, Vol. 11 No. 2, pp. 163-186.

Achmad S. Ruky, 2001. Sistem Manajemen Kinerja. PT Gramedia, Jakarta

Al Mamun, A., Ibrahim, M.D., Yusoff, M.N.H.B. and Fazal, S.A. 2018, "Entrepreneurial leadership, performance, and sustainability of micro-enterprises in Malaysia", Sustainability, Vol. 10 No. 5, p. 1591.

Almaz Sandybayev. 2019. Impact of Effective Entreprenerial Leadership Style on Organizational Performance: Critical Review. International Journal of Economics and Management. Vol. 1 Issue (1) pp 47 - 55, 2019

Benevene, P., Kong, E., Barbieri, B., Lucchesi, M. and Cortini, M. 2017, "Representation of intellectual capital's components amongst Italian social enterprises", Journal of Intellectual Capital, Vol. 18 No. 3, pp. 564-587.

Beltramino, Salvador N., Domingo Garcsayaa-Perez-de-Lema, Luis Enrique Valdez-Juarez. 2020. "The Structural Capital, The Innovation and The Performance Of The Industrial 
Smes." Journal of Intelektual capital Vol. 21 No. 6, hlm.913-945. DOI 10.1108 / JIC01-2019-0020

Bontis, N. 1998, "Intellectual capital: an exploratory study that develops measures and models", Management Decisions, Vol. 36 No. 2, p. 63-76.

Bontis, N., Crossan, MM dan Hulland, J. 2002, "Managing the organizational learning system by aligning stocks and flows", Journal of Management Studies, Vol. 39 No. 4, hlm. 437-469.

Bontis, N., W.C.C Keow, S. Richardson 2000. "Intellectual Capital and business Performance in malaysian Industries". Journal of intellectual capital, Vol. 1 pp 85-100.

Bontis, Nick. Ciambotti, Massimo. Palazzi, Federica. Sgro, Francesca. 2018. "Intellectual capital and financial performance in social cooperative enterprises. Journal of Intellectual Capital'. Emerald Publishing Limited 1469-1930

Claire M Leitch, Thierry Volery. 2017. "Entrepreneurial leadership: Insights and directions". International Small Business Journal. 2017, Vol. 35(2) 147-156.

Daft, Richard. L. 2010. Organization Theory and Design 10Th Edition. SouthWestern: Cengage Learning.

Dollinger, M. J. 1999. Entrepreneurship: Strategies and resources. Prentice Hall, ISBN 0137459939 (Upper Saddle River, NJ).

Efrat, K., Hughes, P., Nemkova, E., Souchon, A. L., \& Sy-Changco, J. 2018. "Leveraging of Dynamic export capabilities for competitive advantage and performance consequences: Evidence from China". Journal of Business Research, 84, 114124. doi:10.1016/j.jbusres.2017.11.018

Gupta, V., MacMillan, I. C., \& Surie, G. 2004. "Entrepreneurial leadership: developing and measuring a cross-cultural construct". Journal of Business Venturing, 19(2), 241260. doi:10.1016/s0883-9026(03)00040-5

Hadijah, HS, Sule, ET and Mulyana, YA. 2015. "The influence of transformational leadership and knowledge of intellectual capital management and its implications for the performance of state-owned bank branch offices in West Java", Journal of Mediterranean Social Sciences, Vol. 6 No. 5, pp. 97-103. https://doi.org/10.1007/s10490-014-9394-8

https://www.cnnindonesia.com/. Diakses tanggal 10 November 2020

https://pddikti.kemdikbud.go.id/ diakses tanggal 01 November 2020

Hussinki, H., Ritala, P., Vanhala, M. and Kianto, A. 2017, "Intellectual capital, knowledge management practices and firm performance", Journal of Intellectual Capital, Vol. 18 No. 4, pp. 904-922.

Imran, R., \& Aldaas, R. E. 2020. "Entrepreneurial leadership: a missing link between perceived organizational support and organizational performance". World Journal of Entrepreneurship, Management and Sustainable Development, doi:10.1108/wjemsd10-2019-0077

Ireland, R. D., Hitt, M. A., \& Sirmon, D. G. 2003."A model of strategic enterpreneurship: The construct and its dimensions". Journal of Management, 29(6), 963-989. https://doi.org/10.1016/S0149-2063(03)00086-2

Kamukama, N. and Sulait, T. 2017, "Intellectual capital and competitive advantage I Uganda's microfinance industry", African Journal of Economic and Management Studies, Vol. 8 No. 4, pp. 498-514.

Peraturan Kementerian Riset, Teknologi, Dan Pendidikan Tinggi Republik Indonesia Nomor 44 Tahun 2015 tentang Standar Nasional Pendidikan Tinggi. Jakarta: Kementrian Riset, Teknologi, dan Pendidikan Tinggi.

Kepmendikbud Nomor 754/P/2020 tentang Indikator Kinerja Utama (IKU)

Keskes, I., Sallan, J.M., Simo, P. and Fernandez, V. 2018, "Transformational leadership and organizational commitment: mediating role of leader-member exchange", Journal of Management Development, No. 3, pp. 271-284.

Khalique, M., Hina, K., Ramayah, T., \& Shaari, J. A. N. bin. 2020. "Intellectual capital in tourism SMEs in Azad Jammu and Kashmir, Pakistan". Journal of Intellectual Capital, 21(3), 333-355. doi:10.1108/jic-11-2018-0206 
Koch, G., Leitner, K. dan Bornemann, M. 2000, Measuring and reporting on intangible assets and yields in European contract research organizations, Paper Prepared for the German OECD Joint Conference, 'Benchmarking Industry-Science Relationships', 16-17 Oktober, Berlin.

Komara, Endang. 2014. "Strategi Perguruan Tinggi dalam Mewujudkan Entrepreneurial Campus" in ATIKAN: Jurnal Kajian Pendidikan, Vol.4(2) December, pp.255-262. Bandung, Indonesia: Minda Masagi Press, FKIP UNSUR Cianjur, and FPOK UPI Bandung, ISSN 2088-1290.

Latif, Fawad Khawaja, et al. 2020. 'Impact of entrepreneurial leadership on project success: mediating role of knowledge management processes", Leadership \& Organization Development Journal, Vol. 41 No. 2, 2020 pp. 237-256. DOI 10.1108/LODJ-07-20190323

Li, S., Ragu-Nathan, B., Ragu-Nathan, T. S., \& Subba Rao, S. 2006. "The impact of supply chain management practices on competitive advantage and organizational performance". Omega, 34(2), 107-124. Doi:10.1016/j.omega.2004.08.002

Luthans, Fred. 2002. Organizational Behavior: 7 th Edition. New York: McGrawHill Inc

Manuel Ibarra, María Rodríguez García, Felipe Hernández-Perlines. 2019. "Intellectual capital, organizational performance and competitive advantage". European Journal of International Management. April 2019 DOI: 10.1504/EJIM.2020.10021761.

Marr, B. (2008), Impacting Future Value: How to Manage your Intellectual Capital, CMA, Mississauga, ON.

Miao, Q., Eva, N., Newman, A. and Cooper, B. 2018, "Ceo entrepreneurial leadership and performance outcomes of top management teams in entrepreneurial ventures: the mediating effects of psychological safety", Journal of Small Business Management, Vol. 57 No. 3, pp. 1119-1135.

Permenristekdikti Nomor 3 Tahun 2018 tentang Penggabungan dan Penyatuan Perguruan Tinggi Swasta.

Rahim, H.L., Abidin, Z.Z., Mohtar, S. and Ramli, A. 2015, "The effect of entrepreneurial leadership towards organizational performance", International Academic Research Journal of Business and Technology, Vol. 1 No. 2, pp. 193-200.

Ramírez Córcoles, Y., Santos Peñalver, JF dan Tejada, Á. 2011, "Intellectual capital in Spanish public universities: the need for stakeholder information", Journal of Kapita Intellectual, Vol. 12 No. 3, pp. 356-376.

Renko, M., El Tarabishy, A., Carsrud, A. L., \& Brännback, M. 2013. "Understanding and Measuring Entrepreneurial Leadership Style". Journal of Small Business Management, 53(1), 54-74. doi:10.1111/jsbm.12086

Rohim, Abdul. Budhiasa, Sujana I Gede. 2019. "Organizational culture as moderator in the relationship between organizational reward on knowledge sharing and employee performance". Journal of Management Development. Vol. 38 No. 7, 2019. pp. 538560. DOI 10.1108/JMD-07-2018-0190.

Sachitra, V., \& Chong, S. C. 2017. "Collective actions, dynamic capabilities and competitive advantage empirical examination of minor export crop farms in Sri Lanka". Journal of Economics, Management and Trade, 20(3), 1-15

Salancik, G. R., \& Pfeffer, J. 1977. Who gets power-and how they hold on to it: A strategic-contingency model of power. Organizational dynamics, 5: 3-21

Sarabi, A., Froese, F.J., Chng, D.H. and Meyer, K.E. 2020, "Entrepreneurial leadership and MNE subsidiary performance: the moderating role of subsidiary context", International Business Review, Vol. 29 No. 3, p. 101672.

Sekaran, uma and bougie Roger, 2017. Research Methods for Business. Seventh edition. Chichester, West Sussex, United Kingdom: John Wiley \& Sons.

Shehzad, Umer. et al. 2014. "The Impact of Intellectual Capital on the Performance of Universities". European Journal of Contemporary Education. Vol. 10, No. 4, pp. 273280, DOI: 10.13187/ejced.2014.10.273 
SHEs: Conference Series 5 (1) (2022) 104- 113

Smart, D. T., \& Conant, J. S. (1994). Entrepreneurial Orientation, Distinctive Marketing Competencies And Organizational Performance. Journal of Applied Business Research (JABR), 10(3), 28-38. https://doi.org/10.19030/jabr.v10i3.5921

Smriti, N. and Das, N. 2018, "The impact of intellectual capital on firm performance: a study of Indian firms listed in COSPI", Journal of Intellectual Capital, Vol. 19 No. 5, pp. 935964.

Soetjipto, Ani. Seda, E. Francisca, Noor, Ruwaid, Ida. Wardani S. B. Eko., Soebagjo Natalia. 2014. "Autonomy and Governance of State Universities Case Studies in the University of Indonesia, the Jakarta State University, and the Syarif Hidayatullah State Islamic University". Jurnal Masyarakat \& Budaya, Volume 16 No. 2 Tahun 2014. Hal 293-304

Soo C, Tian AW, Teo STT, Cordery J. 2017. "Intellectual capital-enhancing HR, absorptive capacity, and innovation". Human Resource Management. 2017;56(3):431-54.

Thapa, A. 2015, "Determinants of microenterprise performance in Nepal", Small Business Economics, Vol. 45 No. 3, pp. 581-594.

Ulum, I. 2012. "Konstruksi Komponen Intellectual Capital untuk Perguruan Tinggi di Indonesia". Jurnal Reviu Akuntansi dan Keuangan, Vol. 2, No. 2, hlm: 251-262.

Undang-Undang Nomor 12 Tahun 2012 tentang Pendidikan Tinggi

Wen-Min Lu. 2012. "Intellectual capital and University performance in Taiwan". Economic Modelling 29 (2012) 1081-1089. DOI:10.1016/j.econmod.2012.03.021

Wang, C. L., Tee, D. D., \& Ahmed, P. K. 2012. "Entrepreneurial leadership and context in Chinese firms: A tale of two Chinese private enterprises." Asia Pacific Business Review, 18(4), 505-530. https://doi.org/10.1080/13602381.2012.690257

Yukl, Gary. 2015, Leadership in Organizations, Seventh Edition, PT. Indeks, Jakarta 